\title{
Modified extracapsular extraction versus endocapsular phacoemulsification: intraoperative and immediate postoperative events
}

\author{
[Extração extracapsular modificada versus facoemulsificação endocapsular: eventos intra e \\ no pós-operatórios imediato] \\ C.S. Honsho ${ }^{1}$, A.P. Oriál ${ }^{1}$, J.A.T. Pigatto ${ }^{1}$, J.L. Laus ${ }^{2}$ \\ ${ }^{1}$ Aluno de pós-graduação - FCAV - UNESP \\ ${ }^{2}$ Faculdade de Ciências Agrárias e Veterinárias \\ Via de Acesso Paulo Donato Castellane, s/n \\ 14884-900 - Jaboticabal, SP
}

\begin{abstract}
The clinical events and variations in intraocular pressure (IOP) that occur in endocapsular phacoemulsification technique were compared to the modified extracapsular extraction technique during the intraoperative and immediate postoperative periods. Phacoemulsification technique caused less corneal edema, less ocular discomfort and fewer postoperative complications than the modified extracapsular extraction technique. The observed increase in postoperative IOP, especially in the case of phacoemulsification, makes pressure monitoring mandatory, as well as the use of ocular hypotensive agents when the IOP exceeds acceptable limits.
\end{abstract}

Keywords: dog, cataract, phacoemulsification, extracapsular extraction, intraocular pressure

\section{RESUMO}

Compararam-se os eventos clínicos e as variações da pressão intra-ocular (PIO) das técnicas facoemulsificação endocapsular e extração extracapsular com modificações, no intra e no pós-operatório imediato. A facoemulsificação resultou em menor edema corneano, menor desconforto ocular e menos intercorrências no pós-operatório em relação à extração extracapsular modificada. É imperativo que se faça o monitoramento da PIO no pós-operatório, uma vez que ela ocorreu na facoemulsificação, e o uso de hipotensores oculares, quando os valores da PIO ultrapassarem os limites aceitáveis.

Palavras-chave: cão, catarata, facoemulsificação, extração extracapsular, pressão intra-ocular

\section{INTRODUCTION}

In dogs, the extraction of the lens for restoration of vision loss due to a cataract has become a routine procedure in veterinary medicine. Surgical success is increasing each day because of the careful selection of patients, technical and instrumental advances, advanced surgical microscopes, correct pre and postoperative use of anti-inflammatory drugs, and increasingly smaller incisions (Dziezyc, 1990; Nasisse et al., 1991).

Until the advent of phacoemulsification, extracapsular extraction was the most widely used and recommended technique for cataract removal in dogs (Whitley et al., 1993). Although widely employed, extracapsular extraction continues to have some disadvantages. The most frequently cited disadvantages include the need

Recebido em 28 de janeiro de 2005

Aceito em 2 de outubro de 2006

*Autor para correspondência (corresponding author)

E-mail: jllaus@fcav.unesp.br

Apoio: FAPESP, processos 98/03153-0 e 99/09479-8, CAPES e CNPq 
for a large corneal incision which causes collapse of the anterior chamber accompanied by intraoperative myosis, impairing removal of the nucleus and cortical remnants, as well as more intense postoperative inflammation (Dziezyc, 1990; Whitley et al., 1993; Linebarger et al., 1999). In addition, corneal edema, a higher frequency of dehiscences, rupture of the posterior capsule, vitreous presentation, hyphema (Whitley et al., 1993), synechiae, greater astigmatism, larger damage to the corneal endothelium, more frequent cases of retinal detachment (Dziezyc, 1990; Williams, et al., 1996) and posterior capsular opacification (Linebarger et al., 1999) have been reported as disadvantages compared to phacoemulsification.

The advantages of phacoemulsification, which is based on the fragmentation of the lens by highfrequency ultrasonic waves and its concomitant aspiration (Dziezyc, 1990; Glover and Constantinescu, 1997), are a shorter duration of surgery, a low risk of vitreous loss, maintenance of the intraocular pressure (IOP) during surgery and less intense iridocyclitis, in addition to a smaller incision and smaller scar accompanied by greater corneal transparency and less astigmatism (Dziezyc, 1990; Glover and Constantinescu, 1997; Linebarger et al., 1999). Disadvantages of phacoemulsification include the high cost of the equipment and the need for a well-prepared team (Glover and Constantinescu, 1997; Linebarger et al., 1999), often requiring prolonged training.

Most complications that result from lens extraction and threaten vision recovery are related to postoperative uveitis. Corneal edema, synechiae, capsular opacification, fibropupillary membranes, pupillary obstruction, vitreous alterations, ocular hypertension, and glaucoma are some of the most important complications that can be minimized by better refinement of the techniques, a shorter duration of the surgery, the correct use of viscoelastic materials, the skill of the surgeon, and the careful use of antiinflammatory drugs (Nasisse and Davidson, 1999).

Cataract extraction is known to cause a transient increase in IOP within the first hours after surgery in both dogs and humans. Therefore, monitoring of the patient, especially during the first 48 hours, has been recommended (Smith et al., 1996; Jürgens et al., 1997). Factors that contribute to ocular hypertension in these cases include blockade of the iridocorneal angle by lenticular remnants (Miller et al., 1987; Smith et al., 1996), soluble proteins, pigments and vitreous humor (Smith et al., 1996; Miller et al., 1997), trauma during the surgical procedure (Smith et al., 1996), breakdown of the bloodaqueous barrier and the presence of inflammatory cells, presence of viscoelastic material, and hemorrhage and synechiae (Meyer et al., 1997; Miller et al., 1997).

The objective of the present study was to monitor the clinical events and variations in IOP during endocapsular phacoemulsification technique compared to the modified extracapsular extraction technique, which was still adopted when complications occurred during phacoemulsification that required conversion to the extracapsular procedure.

\section{MATERIAL AND METHODS}

Twenty-four eyes from 12 adult healthy mongrel dogs of both sexes, weighing 10 to $15 \mathrm{~kg}$, were operated. The study was carried out according to the criteria of the Association for Research in Vision and Ophthalmology (ARVO).

The dogs were pre-selected based on the assessment of general clinical conditions with emphasis on hematimetric indexes (erythrogram, leukogram and thrombogram) and biochemical profile (creatinine, urea and alanine aminotransferase), and evaluation of cardiorespiratory function. The selected animals were also submitted to an ophthalmic semiotechnique using the Schirmer tear test ${ }^{1}$, direct and consensual pupillary reflex test, slit lamp biomicroscopy ${ }^{2}$, applanation tonometry ${ }^{3}$, binocular indirect ophthalmoscopy ${ }^{4}$, fluorescein test $^{5}$, and gonioscopy ${ }^{6}$.

In order to prevent interference from controllable variables, the procedures were compared in the same animal (right and left eyes). The following

${ }^{1}$ Schirmer tear test ${ }^{\circledR}$ - Ophthalmos Fórmulas Oficinais Ltda.

${ }^{2}$ Slit Lamp SL-14 - Kowa Company Ltd.

${ }^{3}$ Tono Pen XL - Mentor Medical Systems

${ }^{4}$ FOH-5 Binocular Indirect Ophthalmoscope - Eytec SA.

${ }^{5}$ Fluorescein strips - Ophthalmos Fórmulas Ofincinais Ltda.

${ }^{6}$ Gonioscope lens - Koeppe, $18 \mathrm{~mm}$, Wayome. 
variables were compared: intraoperative complications, variations in IOP and immediate postoperative clinical events such as photophobia and blepharospasm, conjunctival hyperemia, corneal edema, aqueous humor transparency, and iridocyclitis, as well as the surgical duration of each technique.

The mean IOP measured immediately before the surgical procedures was $13.5 \mathrm{mmHg}$ in the right eyes and $13 \mathrm{mmHg}$ in the left eyes. Since these numbers are reference values, they were included in this item.

The preoperative procedures were initiated 72 hours before the surgery with the oral administration of $1 \mathrm{mg} / \mathrm{kg}$ methylprednisolone ${ }^{7}$ and $0.5 \mathrm{mg} / \mathrm{kg}$ vedaprofen ${ }^{8}$ every 24 hours intervals and topical administration of $1 \%$ prednisolone ${ }^{9}$ every 6 hours. Twenty-four hours before the interventions, daily therapy was started with $30 \mathrm{mg} / \mathrm{kg}$ benzathine and sodium ampicillin ${ }^{10}$ administered subcutaneously at 24 hour intervals. Two hours before the surgery, $1 \%$ atropine sulfate eyedrops ${ }^{11}$ were instilled at 30minute intervals, and $1 \mathrm{mg} / \mathrm{kg}$ flunixin meglumine ${ }^{12}$ was intramuscularly administered 30 minutes before the surgery.

The dogs were intravenously preanesthetized with $0.2 \%$ acepromazine $^{13}$ at the dose of $0.1 \mathrm{mg} / \mathrm{kg}$. After 15 minutes, anesthesia was induced by the intravenous administration of a combination of tiletamine and zolazepam hydrochloride $^{14} \quad(5 \mathrm{mg} / \mathrm{kg})$. Anesthesia was maintained with halogenated gas ${ }^{15}$, vaporized in oxygen, and applied in a semi-closed circuit.

All the animals were submitted to phacoemulsification and modified extracapsular extraction (EE) of the right and left eyes, respectively. Since variations in IOP occur throughout a complete day (Gum et al., 1999),

\footnotetext{
${ }^{7}$ Meticorten - Schering-Plough Indústria Química e Farmacêutica S/A do Brasil

${ }^{8}$ Quadrisol 5 - Intervet S.A.

${ }^{9}$ Pred Fort - Allergan-Frumstost Produtos Farmacêuticos Ltda.

${ }^{10}$ Optacilin - Byk Química e Farmacêutica Ltda.

${ }^{11}$ Atropina 1\% - Allergan-Frumstost Produtos Farmacêuticos Ltda.

${ }^{12}$ Banamine - Schering-Plough Veterinária.

${ }^{13}$ Acepran $0.2 \%$ - Univet S/A.

${ }^{14}$ Zoletyl 50 - Virbac do Brasil Indústria e Comércio Ltda.

${ }^{15}$ Halothane - Laboratórios Wyeth-Whitehall Ltda.
}

the surgical procedures were always performed at the same time and by the same surgeon. A surgical microscope ${ }^{16}$ was used for magnification of the images.

After preparation and antisepsis of the surgical field by routine procedures, canthotomy and mechanical blepharostasis were performed and the eye bulb was fixed with suture stitches to the bulbar conjunctiva and episclera at 3,6 and 9 o'clock positions. An incision was made in the clear cornea with a $3.2 \mathrm{~mm}$ wide angular surgical knife at the 11 and 1 o'clock positions, $2 \mathrm{~mm}$ from the sclerocorneal limbus, followed by capsulotomy. Chondroitin sodium sulfate (4\%) plus $3 \%$ sodium hyaluronate ${ }^{17}$, as well as $1 \%$ sodium hyaluronate ${ }^{18}$, were used as viscoelastic material for filling the anterior chamber by the soft-shell technique proposed by Arshinoff (1999). The corneal incision was widened with corneal scissors, left and right. A continuous curvilinear capsulorrhexis was made with an Utrata forceps. Expression of the nucleus of the lens was performed with the irrigation and aspiration pen of the phacoemulsification apparatus $^{19}$ in the irrigation function (modified technique). Using the same pen in the irrigation and aspiration function, the anterior chamber was washed with balanced saline solution ${ }^{20}$ for removal of remnant material and reconstituted with balanced saline. The corneal incision was closed with simple interrupted stitches using nonabsorbable 9-0 suture ${ }^{21}$. The borders of the canthotomy were approximated with 1-mm simple separate equidistant stitches using absorbable 4-0 suture ${ }^{22}$.

Preparation of the surgical field, canthotomy, mechanical blepharostasis and fixation of the eye bulb were performed as described in the previous item. A tunneled corneal incision was made with a $3.2-\mathrm{mm}$ angular knife at the 11 and 1 o'clock positions, $2 \mathrm{~mm}$ from the sclerocorneal limbus, followed by capsulotomy. The anterior chamber was filled with $4 \%$ chondroitin sulfate and $3 \%$ sodium hyaluronate, followed by $1 \%$ sodium

\footnotetext{
${ }^{16}$ MC-M900 Surgical Microscope - DF Vasconcellos S/A.

${ }^{17}$ Viscoat - Alcon Laboratórios do Brasil Ltda.

${ }^{18}$ Provisc - Alcon Laboratórios do Brasil Ltda.

${ }^{19}$ Universal II Phacoemulsificator - Alcon Laboratórios do Brasil Ltda.

${ }^{20} \mathrm{BSS}$ - Alcon Laboratórios do Brasil Ltda.

${ }^{21}$ Mononylon - Ethicon.

${ }^{22}$ Vicryl 4-0 - Ethicon
} 
hyaluronate, according to the soft-shell technique. Hydrodissection was performed with a $5 \mathrm{~mm}$ syringe provided with a cannula and filled with balanced saline solution, starting with the cannula at the posterior pole of the lens. The lens was then emulsified and aspirated using the phacoemulsification pen in an endocapsular procedure. The following parameters were used: a $75 \mathrm{~cm}$ high flask of balanced saline solution, aspiration flow of 20 to $30 \mathrm{cc} /$ minute, vacuum oscillating between 30 and $180 \mathrm{mmHg}$, and ultrasound power of $60 \%$. A curvilinear capsulorrhexis was made with an Utrata forceps and cortical remnants were aspirated with the irrigation and aspiration pen by the technique of whole crystalline emulsification. Before suture of the margins of the wound, the posterior capsule was polished with the irrigation and aspiration pen. The suture procedures of the cornea and canthotomy were the same as those described for extracapsular extraction.

Immediately at the end of the interventions, $0.2 \mathrm{ml}$ gentamicin $^{23}$ and $0.2 \mathrm{ml}$ betamethasone ${ }^{24}$ diluted in the same syringe were applied subconjunctivally. Atropine (1\%) was instilled every 8 hours for 2 days. Methylprednisolone $(1 \mathrm{mg} / \mathrm{kg})$ was orally administered once a day for 30 consecutive days and then gradually withdrawn. Vedaprofen at the dose of $0.5 \mathrm{mg} / \mathrm{kg}$ was also orally administered once a day. In addition, benzathine and sodium ampicillin at the dose of $30 \mathrm{mg} / \mathrm{kg}$ was subcutaneously applied every 24 hours for 9 consecutive days. Ciprofloxacin eyedrops in combination with chondroitin sulfate ${ }^{25}$ were instilled twice a day for 30 consecutive days. Prednisolone eyedrops were instilled every 4 hours for 30 days and for an additional 30 days at regular 6-hour intervals. Flurbiprofen eyedrops ${ }^{26}$ were instilled at 6-hour intervals during the same period. All the animals wore an Elizabethan collar and also received buprenorphine hydrochloride ${ }^{27}$ at the dose of $10 \mu \mathrm{g} / \mathrm{kg}$ intramuscularly every 8 hours during the first 24 hours after surgery.

\footnotetext{
${ }^{23}$ Garamycin - Schering-Plough Indústria Química e Farmacêutica S/A do Brasil

${ }^{24}$ Diprospan - Schering-Plough Indústria Química e Farmacêutica S/A do Brasil

${ }^{25}$ Ciprovet- Labyes Especialidades Veterinárias.

${ }^{26}$ Ocufen - Allergan-Frumstost Produtos Farmacêuticos Ltda

${ }^{27}$ Temgesic - Schering-Plough Indústria Química e

Farmacêutica S/A do Brasil
}

The duration of the surgery between the corneal incision and the end of suture was measured in the two procedures, as well the duration of ultrasound during phacoemulsification. In addition, complications that occurred during the interventions such as myosis, lens luxation, rupture of the posterior capsule, hemorrhage and vitreous presentation were monitored. Visibility of the anterior chamber in terms of retention of air bubbles was evaluated.

Visual condition, photophobia and blepharospasm, conjunctival hyperemia, corneal edema, aqueous humor transparency and the conditions of the anterior uvea were evaluated in a subjective manner. Slit-lamp microscopy was used for the quantification of the events whose intensity was classified as absent, mild, moderate, and severe.

IOP was measured immediately after the surgical interventions. Three measurements with a $5 \%$ coefficient of variation were obtained and the mean of the three determinations was considered for analysis.

After surgery, IOP was measured at intervals of $1,1,5,2,3,4,5,6,9,12,15,18,21$ and 24 hours. Before each measurement, the ocular surface was desensitized by the topical instillation of proxymetacaine eyedrops ${ }^{28}$.

IOP values were compared between animals by repeated measures analysis of variance using the SAS (User's..., 1999) statistical program, with one technique (phacoemulsification and EE technique) and one time factor (13 time points).

The Tukey test was used to evaluate the differences in mean pressures between techniques. Polynomials were adjusted along time in order to interpret the differences between mean pressure values.

\section{RESULTS}

The mean duration of the interventions from the corneal incision to the end of suture was $23 \pm 4.65$ and $49.3 \pm 10.2$ minutes for the phacoemulsification and EE techniques, respectively. The mean duration of ultrasound

\footnotetext{
${ }^{28}$ Anestalcon - Alcon Laboratórios do Brasil Ltda.
} 
was $3.5 \pm 1.97$ minutes. No myosis was observed during the course of the interventions for either technique.

The formation and retention of air microbubbles were minimal when the phacoemulsificator was used and did not interfere with the visibility of the anterior chamber. Intraoperative complications of EE included three cases $(25 \%)$ of rupture of the posterior capsule, two cases $(16.7 \%)$ of transient intraocular hemorrhage, and one case $(8.3 \%)$ of retina detachment. Regarding phacoemulsification, one case $(8.3 \%)$ of rupture of the posterior capsule and two cases $(16.7 \%)$ of transient intraocular hemorrhage were observed. It should be noted that these eyes were excluded from the statistical analysis of the IOP variables since these complications might interfere with the results (Chee et al., 1999).

Photophobia and blepharospasm were observed in both eyes immediately after the end of surgery, increasing gradually with time. Three hours after surgery, all the animals presented moderate to severe photophobia and blepharospasm. However, these conditions were more severe in eyes submitted to EE. Conjunctival hyperemia was present in all eyes, being moderate at the beginning and becoming severe by the second hour after surgery. Moderate to severe corneal edema was observed in the eyes submitted to EE at 6 to 9 hours of assessment, mainly affecting the upper quadrant (Fig. 1). In the eyes submitted to phacoemulsification, edema was mild between 3 and 4 hours after surgery, progressing to a severe state at 9 hours of assessment. However, edema was restricted to areas close to and above the suture lines (Fig. 2).

Aqueous humor transparency and flare were evaluated. Flare started immediately at the end of the surgical procedures and was moderate to severe in both eyes. Ocular discomfort was observed in most animals, being mild at the beginning but becoming moderate to severe within 4 to 6 hours, regressing to a mild form during the interval between 18 and 24 hours. Ocular discomfort was more marked in the eyes of the EE group compared to those submitted to phacoemulsification.
Means of IOP along the 24 hours of evaluation were $33.75 \pm 5.47$ and $28.03 \pm 4.94 \mathrm{mmHg}$ $(\mathrm{P}<0.035)$ for the phacoemulsification and EE techniques, respectively. Higher pressure levels were observed for eyes submitted to phacoemulsification during all the phases of evaluation.

In the two techniques, IOP differed significantly between time points $(\mathrm{P}<0.0001)$. The IOP remained below $25 \mathrm{mmHg}$ in $7.7 \%$ of the measurements obtained for the eyes submitted to phacoemulsification and in $23.1 \%$ of the measurements obtained for eyes submitted to EE. IOP values remained between 25 and $30 \mathrm{mmHg}$ in $23.1 \%$ of the measurements obtained for the eyes submitted to phacoemulsification and in $46.2 \%$ of those obtained for the eyes submitted to EE. Values ranging from 30 to $40 \mathrm{mmHg}$ were observed in 69.2 and $30.8 \%$ of the evaluations, respectively (Fig. 3). Peaks of ocular hypertension were observed at 9 hours $(39 \mathrm{mmHg})$ after phacoemulsification and at 2 hours $(36.1 \mathrm{mmHg})$ after EE. There were no significant effects of the technique versus time interaction, indicating a similar behavior for both techniques over time $(\mathrm{P}=0.974)$ (Fig. 4). IOP values showed a rapid rise at 2 hours of assessment, followed by a decline at 4 hours. A new increase in pressure levels was observed at 9 hours for both techniques, followed by a decline at 21 hours.

The coefficient of variation for pressure was $28.3 \%$ and the coefficient of determination $\left(\mathrm{r}^{2}\right)$ was 0.742 . The coefficients of determination for phacoemulsification and EE were 0.78 and 0.82 , respectively.

\section{DISCUSSION}

Cataract extraction is currently the elective surgical intervention most frequently performed in humans. In veterinary medicine, adoption of this procedure is increasing every day. The constant refinement of the techniques, together with the careful selection of the patients, the instrumental evolution, the advances in equipment, and the careful use of antiinflammatory drugs have improved the outcome (Nasisse and Davidson, 1999; Lannek and Miller, 2001). 


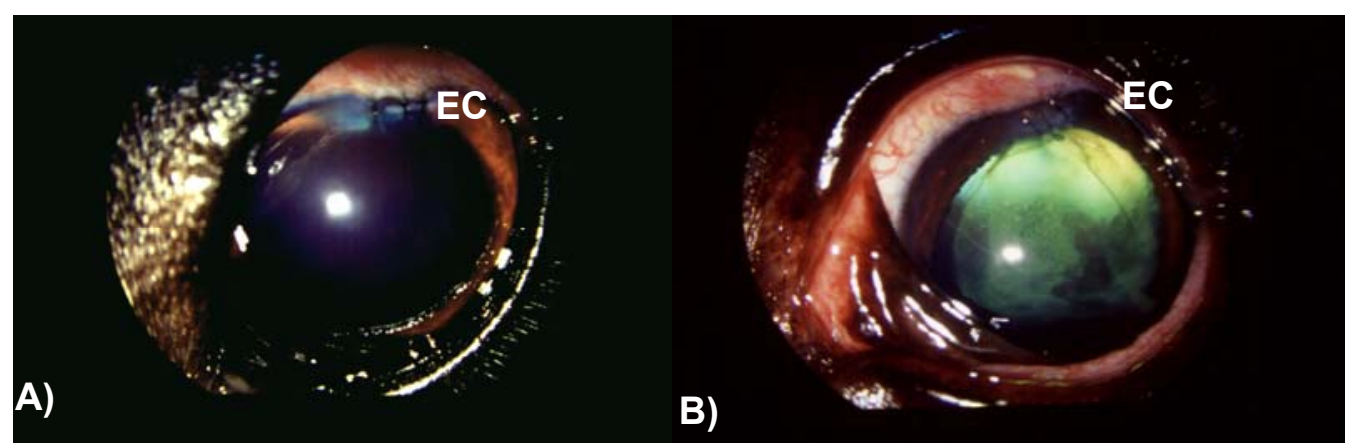

Figure 1. Photographs (A and B) of the eye bulbs of dogs submitted to phacoemulsification obtained 24 hours after surgery. Note the suture stitches, corneal edema (EC) close to the incision site, and mydriasis.

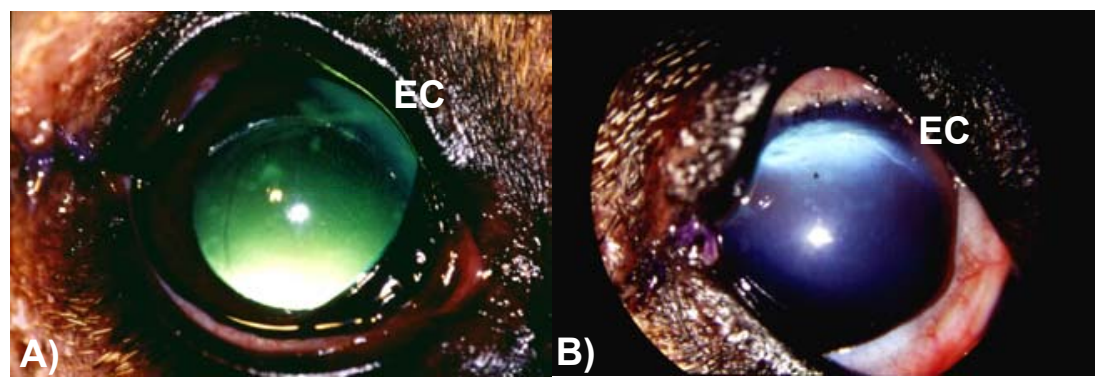

Figure 2. Photographs (A and B) of the eye bulbs of dogs submitted to extracapsular extraction obtained 24 hours after surgery. Note the suture stitches, corneal edema (EC) in the upper and central regions, and mydriasis.

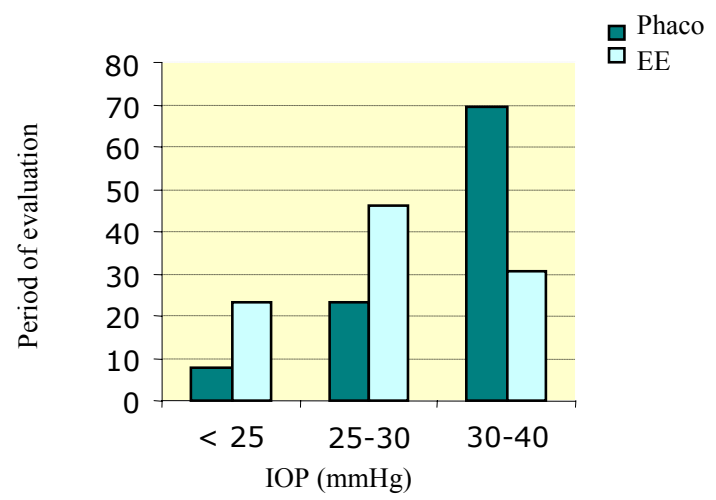

Figure 3. Graphic representation of mean intraocular pressure (IOP) in the eyes of dogs submitted to phacoemulsification (Phaco) and extracapsular extraction (EE) over a period of 24 hours.

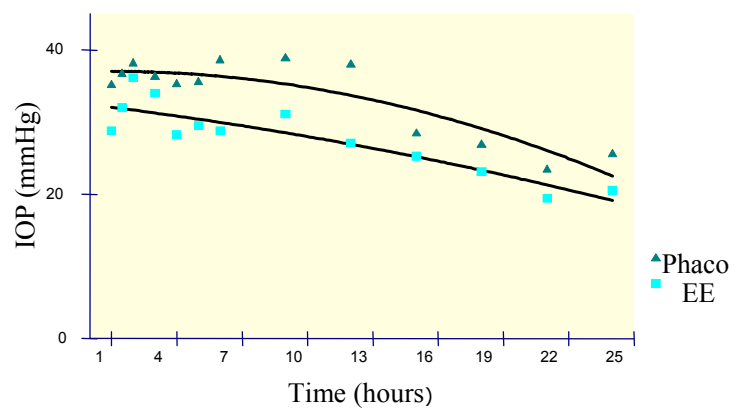

Figure 4. Graphic representation of mean intraocular pressure (IOP) in the eyes of dogs submitted to phacoemulsification (Phaco) and extracapsular extraction (EE) over a period of 24 hours. 
More intraoperative complications were observed for the eyes submitted to EE, including three cases of rupture of the posterior capsule, two cases of intraocular hemorrhage and one case of retina detachment. During phacoemulsification, two cases of intraocular hemorrhage and one case of rupture of the posterior capsule were observed. No case of intraoperative myosis in either procedure was observed.

Photophobia, ocular discomfort, blepharospasm, conjunctival hyperemia and flare were observed mainly in the eyes submitted to EE. Corneal edema of greater intensity set in immediately after intervention in these eyes; whereas in those submitted to phacoemulsification, edema was discrete at 3 to 4 hours of evaluation and was limited to the suture line. The rapid development of intraocular inflammation in the eyes submitted to EE explains the marked corneal edema observed. The greater surgical damage to the ocular surface provoked by this technique leads to an inflammatory response accompanied by the release of prostaglandins and neutrophil and macrophage recruitment (El-Harazi and Feldman, 2001; Saccà et al., 2001). Chee et al (1999) compared postoperative inflammation based on flare intensity in patients submitted to phacoemulsification and EE, and observed more marked inflammation in the eyes submitted to the latter technique. Since capsulorrhexis, nucleus extraction and the type of intraocular lens were the same, the authors attributed the findings to the larger surgical incision performed in EE.

Flare results from the dilatation of vessels in the iris and ciliary body and from an increased permeability of the blood-aqueous barrier mediated, to a large extent, by the release of prostaglandins (Krohne and Vestre, 1987; Millichamp et al., 1991). Despite pre and postoperative anti-inflammatory therapy, moderate to severe flare was observed. Myosis and flare are complications resulting from intraocular procedures which prolong postoperative recovery and predispose to the formation of synechiae (Brightman et al., 1981; Millichamp et al., 1991). Although flare of moderate to severe intensity was present, no synechiae were observed.
Dispersive and cohesive viscoelastic agents are necessary in cataract surgery. The use of a combination of $3 \%$ sodium hyluronate- $4 \%$ chondroitin sulfate (dispersive) and 1\% sodium hyaluronate (cohesive) has been recommended (Arshinoff, 1999; Wilkie and Willis, 1999). Pigatto (2004) studied corneal endothelial repercussions in dogs submitted to phacoemulsification and $\mathrm{EE}$ using the same combination of viscoelastic agents in a soft-shell technique. The author observed that despite cell losses the use of viscoelastic agents minimized the damage to the corneal endothelium.

In the present study, the maximum IOP was observed at 9 hours $(39 \mathrm{mmHg})$ for phacoemulsification, while in EE the maximum value of $36.1 \mathrm{mmHg}$ was observed at 2 hours after surgery, with no significant difference between the two techniques. With respect to phacoemulsification, no correlation could be established between the duration of ultrasound and a higher IOP, in contrast to the findings of Smith et al. (1996). IOP is known to remain elevated during the first 24 hours after surgery, especially in eyes submitted to phacoemulsification (Jürgens et al., 1997; Meyer et al., 1997), despite washing of the anterior chamber with the irrigation and aspiration pen at the end of the surgery.

Small incisions and highly viscous substances contribute to the occurrence of postoperative ocular hypertension (Jürgens et al., 1997). Small incisions promote better coaptation of the surgical wound but impair drainage of the viscoelastic agents, contributing to the occurrence of ocular hypertension (Jürgens et al., 1997; Chahory et al., 2003). Reduced drainage of the aqueous humor due to mechanical obstruction of the drainage angle with lenticular remnants, plasma proteins and inflammatory cells (Meyer et al., 1997), as well as narrowing of the trabecular meshwork, as a result of edema, favor an increase in IOP (Millichamp et al., 1991; Millichamp et al., 1991). Pretreatment with atropine sulfate increases the resistance of the trabecular meshwork to drainage of aqueous humor due to its action on the ciliary musculature and stabilization of the bloodaqueous barrier predisposing to obstruction of the iridocorneal angle (Millichamp et al., 1991; Collins and Moore, 1999). In the presence of intraocular inflammation, the IOP tends to 
decrease after some hours (Millichamp et al., 1991), as observed in the present study. Controversies exist regarding the use of hypotensive agents after cataract surgery since most eyes tolerate transient increases in IOP. Increased or prolonged episodes of hypertension, however, may cause pain, corneal edema, ischemia or occlusion of retinal vessels (Browning et al., 2002). Chahory et al. (2003) reported the importance of monitoring IOP during the first hours after surgery, without necessarily using hypotensive agents, except in cases in which the increase is exaggerated. Alves et al. (2001) emphasized that patients submitted to cataract surgery, mainly elderly individuals, may present an impaired blood supply to the optic nerve and retina, which will be aggravated by transient increases in IOP. It should be noted that postoperative hypotony, although rare in intraocular surgeries in which a small incision is made, might be as damaging as hypertension since, if it persists, it can predispose to retina detachment and choroid hemorrhage.

\section{CONCLUSIONS}

Phacoemulsification caused less photophobia, blepharospasm, conjunctival hyperemia, flare and fewer other complications than EE. An increase in IOP was observed during the first 24 hours after surgery irrespective of the surgical technique. The use of dispersive and cohesive viscoelastic agents minimized the formation and retention of air microbubbles, contributing to the visibility of the anterior chamber during phacoemulsification. Procedures showed that phacoemulsification is more advantageous.

\section{REFERENCES}

ALVES, M.C.; FARIA, T.M.; RASKIN, E. et al. Hipertensão intra-ocular após facoemulsificação e implante de lente intra-ocular. Rev. Bras. Ophthalmol., v.60, p.432-436, 2001.

ARSHINOFF, S.A. Dispersive-cohesive viscoelastic soft Shell technique. J. Cataract Refract. Surg., v.25, p.167-173, 1999.

BRIGHTMAN, A. H.; HELPER, L. C.; HOFFMAN, W.E. Effect of aspirin on aqueous protein values in the dog. J. Am. Vet. Med. Assoc., v.178, p.572-573, 1981.
BROWNING, A.C.; ALWITRY, A., HAMILTON, R. et al. Role of intraocular pressure measurement on the day of phacoemulsification cataract surgery. J. Cataract Refract Surg., v.28, p.1601-1606, 2002.

CHAHORY, S.; CLERC, B.; GUEZ, J. et al. Intraocular pressure development after cataract surgery: a prospective study in 50 dogs (19982000). Vet. Ophthalmol., v.6, p.105-112, 2003.

CHEE, S-P.; TI, S-E.; SIVAKUMAR, M. et al. Postoperative inflammation: extracapsular cataract extraction versus phacoemulsification. $J$. Cataract Refract. Surg., v.25, p. 1280-1285, 1999.

COLLINS, B.K.; MOORE, C.P. Diseases and surgery of the canine anterior uvea. In: GELATT, K.N. (Ed.). Veterinary ophthalmology. 3.ed. Philadelphia: Lea \& Febiger, 1999. p.755-795.

DZIEZYC, J. Cataract surgery: current approaches. Vet. Clin. N. Am.: Small Anim. Pract., v.20, p.737-754, 1990.

EL-HARAZI, S.M.; FELDMAN, R.M. Control of intra-ocular inflammation associated with cataract surgery. Curr. Opin. Ophthalmol., v.12, p.4-8, 2001

GLOVER, T.D.; CONSTANTINESCU, G.M. Surgery for cataracts. Vet. Clin. N. Am.: Small Anim. Pract., v. 27, p.1143-1173, 1997.

GUM, G.G.; GELATT, K.N.; OFRI, R. Phisiology of the eye. In: GELATT, K. N. Veterinary ophthalmol. 3.ed. Philadelphia: Lea \& Febiger, 1999. p.151-181.

JÜRGENS, I.; MATHEU, A.; CASTILHA, M. Ocular hypertension after cataract surgery: a comparision of three surgical techniques and two viscoelastics. Ophthalmol. Surg. Lasers, v.28, p.30-36, 1997.

KROHNE, S.D.G.; VESTRE, W.A. Effects of flunixin meglumine an dexamethasone on aqueous protein values after intraocular surgery in the dog. Am. J. Vet. Res., v.48, p.420-422, 1987.

LANNEK, E.B.; MILER, P.E. Development of glaucoma after phacoemulsification for removal of cataracts in dogs: 22 cases (1987-1997). J. Am. Vet. Med. Assoc., v.218, p.70-76, 2001. 
LINEBARGER, E.J.; HARDTEN, D.R.; SHAH, G.K. et al. Phacoemulsification and modern cataract surgery. Surv. Ophthalmol., v.44, p.123147, 1999.

MEYER, M.A.; SAVITT, M.L.; KOPITAS, E. The effect of phacoemulsification on aqueous outflow facility. Ophthalmology, v.104, p.12211227, 1997.

MILLER, P.E.; STANZ, K.M.; DUBIELZIG, R.R. et al. Mecanisms of acute intraocular pressure after phacoemulsification lens extraction in dogs. Am. J. Vet. Res., v.58, p.1159$1165,1997$.

MILLER, T.R.; WHITLEY, R.D.; MEEK, L.A. et al. Phacofragmentation and aspiration for cataract extraction in dogs: 56 cases (19801984). J. Am. Vet. Med. Assoc., v.190, p.15771580, 1987.

MILLICHAMP, N.J.; DZIEZYC, J., ROHDE, B.H. et al. Acute effects of anti-inflammatory drugs on neomydium:yttrium aluminum garnet laser-induced uveitis in dogs. Am. J. Vet. Res., v.52, p.1279-1284, 1991.

MILLICHAMP, N.J.; DZIEZYC, J.; OLSEN, J. W. Effect of flurbiprofen on facility of aqueous outrflow in the eyes of dogs. Am. J. Vet. Res., v.52, p.1448-1454, 1991.

NASISSE, M.P.; DAVIDSON, M.G.; JAMIESON, V. E. et al. Phacoemulsification and intraocular lens implantation: a study of technique in 182 dogs. Progr. Vet. Comp. Ophthalmol., v.1, p.225-232, 1991.

NASISSE, M.P.; DAVIDSON, M.G. Surgery of the lens. In: GELATT, K. N. Veterinary ophthalmology. 3.ed. Philadelphia: Lea \& Febiger, 1999. p.827-856.

PIGATTO, J.A.T. Extração extracapsular do cristalino, comparativamente à facoemlulsificação, com enfoque nas repercussões endoteliais corneanas em cães (Canis familiares - Linnaeus, 1758). 2004. 112f. Tese (Doutorado em Cirurgia) - Faculdade de Medicina Veterinária e Zootecnia, Universidade de São de Paulo, São Paulo.

SACCÀ, S.; MARLETTA, A.; PASCOTTO, A. et al. Daily tonometric curves after cataract surgery. Br. J. Ophthalmol., v.85, p.24-29, 2001.

SMITH, P.J.; BROOKS, D.E.; LAZARUS, J.A. et al. Ocular hipertension following cataract surgery in dogs: 139 cases (1992-1993). J. Am. Vet. Med. Assoc., v. 209, p. 105-111, 1996.

USER'S guide: statistics. 8.02. Cary. NC: SAS Institute, 1999.

WHITLEY, R.D.; McLAUGHLIN, S.A.; WHILTLEY, E. M. et al. Cataract removal in dogs: The surgical techniques. Vet. Med., v.88, p.859-866, 1993.

WILKIE, D.A.; WILLIS, A.M. Viscoelastic materials in veterinary ophthalmology. Vet. Ophthalmol., v.2, p.147-153, 1999.

WILLIAMS, D.L.; BOYDELL, I.P.; LONG, R.D. Current concepts in the management of canine cataract: a survey of techniques used by surgeons in Britain, Europe and USA and a review of recent literature. Vet. Rec., v.138, p.347-353, 1996. 